Rheumatoid arthritis (RA) is characterized by an abnormal cellular and cytokine infiltration of inflamed joints. This study addresses a previously unrecognized interaction between neutrophilic-myeloperoxidase (MPO) and macrophages (Mø) which could explain the perpetuation of in flam mation associated with RA. A monoarticular arth ritis was induced in female Lewis rats by in jection of streptococcal cell wall ex tracts (PG-APS). After swelling and erythema subsided, joints were re-injected with one of the following: porcine MPO or partially inactivated MPO (iMPO). In jection with eith er MPO or iMPO induced a 'flare' of experimental RA. Blocking the Mø-mannose receptor by mannans, ablated exacerbation of disease. These results indicate that MPO or iMPO can play a pivotal role in the perpetuation but not initiation of th is RA model.

Key words: Autoimmunity, Peroxidases, TNF- $\alpha$, Rhe umatoid arthritis, Reactive oxygen intermediates

\section{Perpetuation of inflammation associated with experimental arthritis: the role of macrophage activation by neutrophilic myeloperoxidase}

\author{
Monique P. Gelderman, ${ }^{1}$ Rodney Stuart, ${ }^{2}$ \\ David Vigerust, ${ }^{2}$ Steven Fuhrmann, \\ Doris L Lefkowitz, ${ }^{2, C A}$ Robert C. Allen, ${ }^{3}$ \\ Stanley S. Lefkowitz ${ }^{4}$ and Susan Graham ${ }^{4}$
}

${ }^{1}$ National Institutes of Health, Bethesda, MD 20931, USA, ${ }^{2}$ Texas Tech University, Lubbock, TX 79409, USA, ${ }^{3}$ Severance and Associates, P.A., San Antonio, TX 78207, USA, ${ }^{4}$ Texas Tech Health Sciences Center, Lubbock, TX 79430, USA

\footnotetext{
${ }^{\mathrm{CA}}$ Corresponding Author

Fax: 806-742-2712

Email: xlefk@ttacs.ttu.edu
}

\section{Introduction}

Rhe umatoid arthritis (RA) is an inflammatory autoimmune disease of unknown etiology. ${ }^{1-3}$ It is known that this inflammatory disease affects the synovial membranes of various joints and that there is de novo vascularization beneath the synovial lining along with an orchestrated infiltration of the joint by $\mathrm{T}$ and $\mathrm{B}$ lymphocytes as well as macrophages $(\mathrm{M} \varnothing)$. Several investigators have reported the association of $\mathrm{M} \varnothing$ with the pathology of RA. ${ }^{4-7}$ Moreover, it has been reported that $80-100 \%$ of those cells which line the synovium are Mø. ${ }^{8}$ In addition to the Mø, neutrophils are abundant in the synovial fluid and it has been reported that both cell types are found in a state of heightened activation. ${ }^{2,3,8}$ It has recently been reported that Mø directly influence a neutrophil-dependent inflammatory response and that the neutrophil, in turn, recruits and activates Mø. ${ }^{9}$

Along with the presence of the above cell types, it is documented that there are abnormal levels of numerous cytokines in an RA joint. ${ }^{1,8}$ Among the cytokines present are the following: tumor necrosis factor $\alpha$ (TNF $\alpha$ ), IL-1, IL-6, IL-8 as well as others. ${ }^{7,10,11}$ However, of the cytokines reported to be present in the RA joint, TNFa is believed to be pivotal to the disease process. ${ }^{1,7}$ Since TNF $\alpha$ initiates a cascade of pro-inflammatory cytokines, ${ }^{7,10,11}$ the central role of this cytokine in the disease process is not surprising. Several investigators have reported that the primary source ofTNFa in an RA joint is the Mø; ${ }^{12,13}$ however, the factor(s) which are responsible for stimulation of these cells to secrete TNF $\alpha$ have not be identified.

Since it has been reported that neutrophils are abundant in the synovial fluid of the RA joint, ${ }^{2,3,5}$ one would also expect myeloperoxidase (MPO) to be present. In fact, other investigators have documented the presence of enzymatically active MPO as well as $16-29 \mu \mathrm{g} / \mathrm{ml}$ of enzymatically inactive MPO in RA joints. ${ }^{14,15}$ These studies indicate that both forms of the enzyme may be associated with RA.

In other studies completed in this laboratory, data indicated that recombinant human MPO and enzymatically inactive MPO enhanced the following resident murine Mø functions: (1) respiratory burst, ${ }^{16,17}$ (2) secretion of TNF $\alpha$, IL-6, IL-8, and granulocyte-Mø colony stimulating factor (GM-CSF) (unpublished data), and (3) phagocytosis and intracellular killing of Candida albicans and E. coli. ${ }^{16-18}$ Myeloperoxidase also induced elevated titers of TNF $\alpha$ and IFN $\alpha / \beta$ in vivo. ${ }^{19}$ Since it has been reported that neutrophils, MPO, enzymatically inactive MPO, and Mø are present in an inflamed RA joint, the present study was undertaken to determine if the interaction between 
either MPO or enzymatically inactive MPO and Mø could contribute to the 'chronicity' of inflammation associated with experimental RA. A Lew is rat model was employed to investigate the effect of neutrophilic MPO on exacerbation of this disease. The disease was induced using a single intra-articular injection of streptococcus A cell wall fragments (PG-APS). After development of ex perimental RA, either porcine MPO or partially inactivated porcine MPO was injected into the same joint to determine what effect this enzyme had on exacerbation of the disease. For convenience, in the remainder of this manuscript, RA will be used to designate mono-articular experimental RA unless otherw ise stated.

\section{Materials and Methods}

\section{Myeloperoxidase}

The use of rat MPO would have been preferred, but it was not available. Highly purified porcine MPO was generously provided by Dr R.C. Allen. The mannose content of this preparation was $4.6 \%$ and it contained 1539 units/ml of activity using o-dianisidine as a substrate. Cathepsin G, a serine protease, has been reported to be present in neutrophils. Trypsin, another serine protease, was used to generate inactive MPO as follows: Myeloperoxidase was partially inactivated by exposure to trypsin-Sepharose $4 \mathrm{~B}$ gel slurry (Worthington Biochemicals, Freehold, NJ). Prior to mixing the MPO and the gel slurry together, a 1:12 dilution of $\mathrm{MPO}$ was heated to $70^{\circ} \mathrm{C}$ for $10 \mathrm{~min}$. After the solution cooled to below $37^{\circ} \mathrm{C}$, the diluted MPO was mixed with the slurry at a $4: 1$ ratio of MPO to trypsin for the digestion. Digestion was allowed to proceed for $6 \mathrm{~h}$ at $37^{\circ} \mathrm{C}$. After this incubation, the supernatant was collected, aliquoted, and stored at $-20^{\circ} \mathrm{C}$ until used. This preparation of MPO exhibited 123 units $/ \mathrm{ml}$ of activity as measured by o-dianisidine. For the remainder of this manuscript, the partially inactivated MPO will be referred to as iMPO.

\section{Animals}

Age matched female Lewis rats weighing approximately $180 \mathrm{~g}$ were obtained from Harlan Sprague Dawley, Indianapolis, IN. Animals were cared for and housed in a facility according to the guidelines of the Animal Welfare Act.

\section{Reagents}

The Limulus amebocyte lysate (LAL) assay was used to test all reagents for LPS contamination. The stock MPO preparation contained $\leq 0.08 \mathrm{ng} / \mathrm{ml}$ of LPS. The amount of LPS in the inactivated MPO $w$ as the same after exposure to trypsin beads. Materials for the LAL assay were purchased from Associates of Cape Cod (Woodshole, MA). Immunocytochemistry reagents which were purchased from Sigma (St Louis, MO) included: diethylpyrocarbonate, Mayer's hematoxylin solution, bovine serum albumin (fraction V) (BSA), and diaminobenzidine. Other reagents which were purchased from Fisher Scientific (Pittsburgh, PA) were: Superfrost-plus microscope slides, xylene, permount, and TRIS base. Saccharomyces cervisiae was the source of mannans which was purchased from Fluka Biochemika, Switzerland. Mannosylated bovine serum albumin (M-BSA) was purchased from E.Y. Laboratories (San Mateo, CA).

\section{Cells}

Resident rat peritoneal Mø were collected by peritoneal lavage similar to the procedure previously described by the present investigators. ${ }^{17,18}$ Briefly, after the cell suspension was removed from the abdominal cavity and centrifuged at $1000 \mathrm{rpm}$ for $10 \mathrm{~min}$ at $4^{\circ} \mathrm{C}$, red blood cells were lysed using hypotonic phosphate buffered saline (PBS). After centrifugation, the supernatants were decanted and the peritoneal cells diluted to $1.2 \times 10^{6} \mathrm{cells} / \mathrm{ml}$ and resuspended in Dulbecco's modified Eagle's medium (Gibco, Long Island, NY) containing HEPES (Sigma), sodium bicarbonate, and gentamicin sulfate (Sigma). Subsequent to a 2-hour incubation, monolayers were washed vigorously with media to remove non-adherent cells. Using staining procedures, it was determined that the adherent cell cultures were $\geq 99 \%$ pure Mø. Subsequently, Mø monolayers were exposed to different concentrations of either MPO or iMPO. After various incubation periods, supernantants were collected and stored at $-70^{\circ} \mathrm{C}$ until used. ELISA kits for TNF $\alpha$ were purchased from Genzyme (Cambridge, $\mathrm{MA})$, and the manufacturer's instructions were followed.

\section{Arthritis Model}

Female Lew is rats were used for the induction of a mono-articular arthritis. The right ankle joint (which was the negative control) was injected with $10 \mu \mathrm{l}$ of normal saline. The left ankle joint (which was the experimental joint) was initially injected with $10 \mu \mathrm{l}$ of a sterile, aqueous suspension of PG-APS (a generous gift from Dr S. Lichtman, University of North Carolina, Chapel Hill, NC) containing a dose equivalent to $2 \mu \mathrm{g}$ of rhamnose. ${ }^{20,21}$ A 27 gauge 0.5 inch needle was inserted though the Achilles tendon above the calcaneous into the vicinity of the tibiotalar joint. For all injections, the animals were sedated by ether inhalation.

After IA injection of PG-APS, the joints increased in diameter by approximately $1-2 \mathrm{~mm} \quad(5.8$ to $7.0-8.0 \mathrm{~mm}$ ) within $24-48 \mathrm{~h}$. Over a period of $7-21$ days, these joints decreased in swelling to approximately $6.5 \mathrm{~mm}$. Since no further decrease in diameter 
was noted over a period of 2 months, $6.5 \mathrm{~mm}$ was considered to be 'baseline' level of swelling. Therefore, when a PG-APS treated joint measured $6.5 \mathrm{~mm}$, both ankle joints were re-injected: the right joint received $10 \mu \mathrm{l}$ of normal saline, and the left joint received $10 \mu \mathrm{l}$ of various treatment solutions. Those joints which increased in size by a minimum of $0.5 \mathrm{~mm} 24-48$ hours after re-injection were considered positive for inflammation. On a daily basis, the peri-articular swelling of both treated and control ankle joints was monitored. The peri-articular swelling was measured with a caliper starting on day zero, and continued daily until the study was completed.

\section{Histology}

Post-mortem, both hind legs were harvested and processed as previously described by other investigators. ${ }^{20-22}$ The severity of the arthritis was scored on a scale of 0-3 for synovial hyperplasia and inflammation, tissue erosion, and the presence of neutrophils. All histological sections were read blinded by Suzanne Graham, MD, Department of Pathology at Texas Tech University Health Sciences Center.

\section{Immunocytochemistry}

Post-mortem, treated (left) and control (right) ankle joints were harvested and prepared for immunocytochemistry. $^{22}$ Sections were placed on Superfrost/ Plus slides and deparaffinized. Subsequently, sections were treated with $3 \% \mathrm{H}_{2} \mathrm{O}_{2}$ to destroy endogenous peroxidase activity. After $\mathrm{H}_{2} \mathrm{O}_{2}$ treatment, sections were incubated with a rabbit polyclonal antibody to TNFo (Calbiochem, La Jolla, CA) overnight at $4^{\circ} \mathrm{C}$. Normal rabbit IgG (Sigma) was used as a control. After several washes with PBS buffer, sections were incubated with biotinylated anti-rabbit $\operatorname{IgG}$ for $30 \mathrm{~min}$ at room temperature. Incubation for an additional $30 \mathrm{~min}$ was performed with an avidin:biotinylated enzyme complex (VECTASTAIN ABC system, Vector Laboratories, Burlingame, CA). Diaminobenzidine was used as a substrate. Subsequently, sections were counterstained with hematoxylin and examined mic roscopically.

\section{Statistical analysis}

A two-tailed Student's t-test was used to determine significance between groups. Most data are presented as the mean \pm S.E.M.

\section{Results}

Since it is known that TNF $\alpha$ is pivotal to human RA and initiates a cascade of pro-inflammatory cytokines, initial experiments were done to determine if either

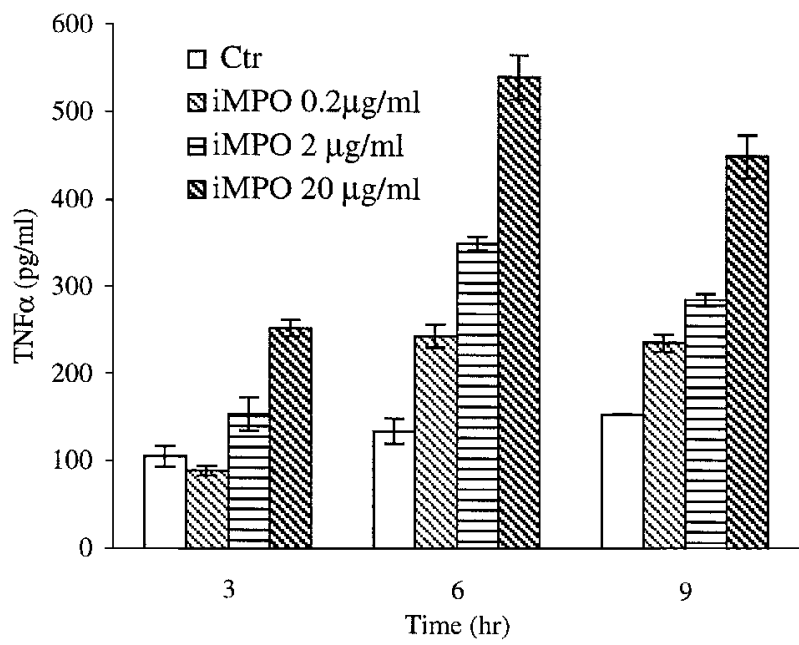

FIG. 1. Induction of tumor necrosis factor-alpha (TNF $\alpha$ ) by enzymatically inactive myeloperoxidase (iMPO). Resident rat peritoneal macrophage (Mø) were cultured in a 96 well Costar plate. After a 2-hour incubation, the cells were washed, and either treatments or media alone were added. The supernatants from treated and control wells were collected and stored at $-70^{\circ} \mathrm{C}$ until used for an ELISA. Manufacturer's instructions were followed.

MPO or iMPO could induce TNF $\alpha$ secre tion by Mø in vitro. Ex posure of resident rat peritoneal Mø to either MPO or iMPO induced markedly higher titers of TNF $\alpha$ than that obtained from the control cultures. It can be noted from Fig. 1 that iMPO induced a dosedependent increase in TNF $\alpha$ secretion with peak titers being obtained at $6 \mathrm{~h}$. If, however, MPO was employed, an increase in TNFa was observed with $20 \mu \mathrm{g} / \mathrm{ml}$ but not with $0.2 \mu \mathrm{g} / \mathrm{ml}$. At the highest concentration $(20 \mu \mathrm{g})$, MPO induced approximately $50 \%$ less cytokine than iMPO (data not shown). It should be noted that the level of endotoxin in the most concentrated preparation of either MPO or iMPO employed in these studies contained $\leq 8 \times 10^{-3} \mathrm{ng} / \mathrm{ml}$. This level of endotoxin did not induce TNFa in vitro as determined by ELISA (data not shown).

The next set of experiments was done in vivo to determine if either form of the enzyme alone could initiate arthritis. After an initial injection of saline, animals were injected weekly for 3 consecutive weeks with various concentrations of either MPO or iMPO. In addition, a non-specific protein, mannosylated BSA, was also tested. None of these substances initiated the clinical symptoms of arthritis as noted by swelling and erythema. Also, since LPS contamination is ubiquitous, and this substance activates Mø, levels of endotoxin ( $10 \mathrm{ng} /$ joint $)$ that were approximately $1 \times 10^{5}$ times higher than the concentration found in any of the solutions employed in this study were injected IA. The same results as that for other initiators were obtained, i.e. there were no clinical symptoms of arthritis as determined by swelling and erythema (data not shown). 

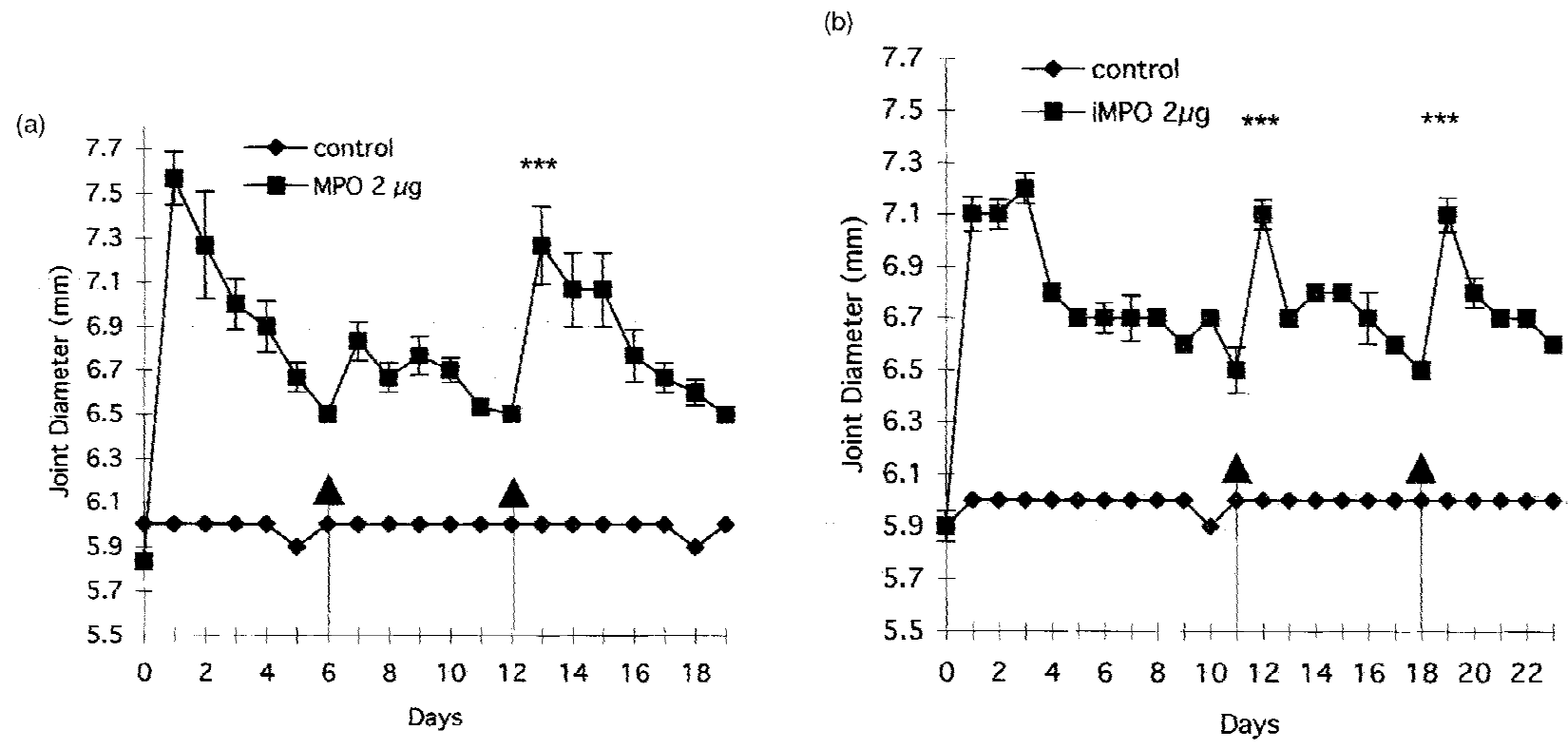

FIG. 2. (a) Exacerbation of peri-articular swelling after re-injection of pre-treated joints with enzymatically active myeloperoxidase (MPO). On day 0 , animals were injected with $10 \mu$ l PG-APS ( $2 \mu \mathrm{g}$ of rhamnose/joint) in the left ankle joint and $10 \mu \mathrm{l}$ normal saline in the right ankle joint. After the treated joint returned to 'baseline' level of swelling/erythema, the exacerbation regimen was started. On days 6 and 12 (as depicted by the arrows), animals were re-injected with $10 \mu$ I MPO (left ankle joint) and $10 \mu \mathrm{l}$ normal saline (right ankle joint). These values represent the results of at least 3-5 animals. The experiment was repeated at least once. ${ }^{* * *} P \leq 0.001$. (b) Periarticular swelling after re-injection of PG-APS pre-treated joints with enzymatically inactive myeloperoxidase (iMPO). On day 0 , animals were injected with $10 \mu$ l PG-APS $(2 \mu \mathrm{g}$ of rhamnose/ joint) in the left ankle joint and $10 \mu \mathrm{l}$ normal saline in the right ankle joint. After the treated joint returned to 'baseline', the exacerbation regimen was started. On days 11 and 18 (as depicted by the arrows), animals were re-injected with $10 \mu$ l iMPO $(2 \mu \mathrm{g} /$ joint): left ankle joint and $10 \mu \mathrm{l}$ normal saline (right ankle joint). Graphed values represent the results of 3-5 animals. The experiment was repeated at least once. The concentrations reflected in the graph are those present in the joint. ${ }^{* * *} P \leq 0.001$

Since it had been established that LPS at the above concentration could not initiate arthritis, a number of animals were injected IA with LPS after PG-APS treatment. When $10 \mathrm{ng} /$ joint of LPS were injected IA, there were no clinical symptoms observed. It should be noted that this cycle was repeated twice with identical results. When $15 \mu \mathrm{g}$ of BSA (a substance to which Lew is rats should not respond $)^{23}$ was repeatedly injected IA after PG-APS, once again, no clinical symptoms were observed (data not shown).

Various concentrations of either MPO or iMPO were employed after arthritis was initiated with PGAPS. Concentrations employed varied between 0.2 and $20 \mu \mathrm{g}$ in $10 \mu \mathrm{l}$. If $0.2 \mu \mathrm{g}$ was injected IA, approximately $50 \%$ of the animals exhibited RA after each injection series. If $20 \mu \mathrm{g}$ were employed, all animals developed RA with $66 \%$ displaying 'chronic' arthritis. That is, the joints did not return to 'baseline' swelling within a 2 month period after the initial MPO injection (data not shown). If $2 \mu \mathrm{g}$ of MPO were injected after PG-APS, the initial response was not positive, whereas, a second injection exacerbated a flare of the disease (Fig. 2a). How ever, when $2 \mu \mathrm{g}$ of iMPO were injected after PG-APS, all animals exhibited swelling and erythema in the injected joints. This pattern was repeated after a second IA injection of iMPO was administered (Fig. 2b). Because of the above responses, $2 \mu \mathrm{g} / 10 \mu \mathrm{l}$ were employed for the remainder of the study.

As stated previously, in vitro experiments had demonstrated that either MPO or iMPO could induce TNFo. Therefore, experiments were done to determine if TNFa was pivotal in the exacerbation of arthritis observed after IA injections of either MPO or iMPO. After joints were injected with PG-APS and swelling as well as erythema had returned to 'baseline', IA injections of MPO alone, iMPO alone, antiTNFo alone, MPO and anti-TNFo, or iMPO and antiTNFo were administered. Figure 3 depicts the results of an MPO+anti-TNFa experiment. The presence of anti-TNF- $\alpha$ completely ablated the effect of MPO w ith respect to ex acerbation of a flare of RA. Similar results were obtained with iMPO (data not shown).

Myeloperoxidase is known to be taken up by Mø via the Mø mannose receptor (MMR). ${ }^{24}$ It was hypothesized that blocking the MMR should inhibit clinical symptoms. Mannans are frequently used to block the MMR; ${ }^{25}$ the refore, after joints were injected with PG-APS and had returned to 'baseline' level of swelling, IA injections were administered with one of the following: mannans alone, MPO alone, iMPO alone, MPO and mannans, or iMPO and mannans. Mannans alone did not elicit any joint swelling or erythema. When MPO was injected in combination with mannans, the same results were obtained as 


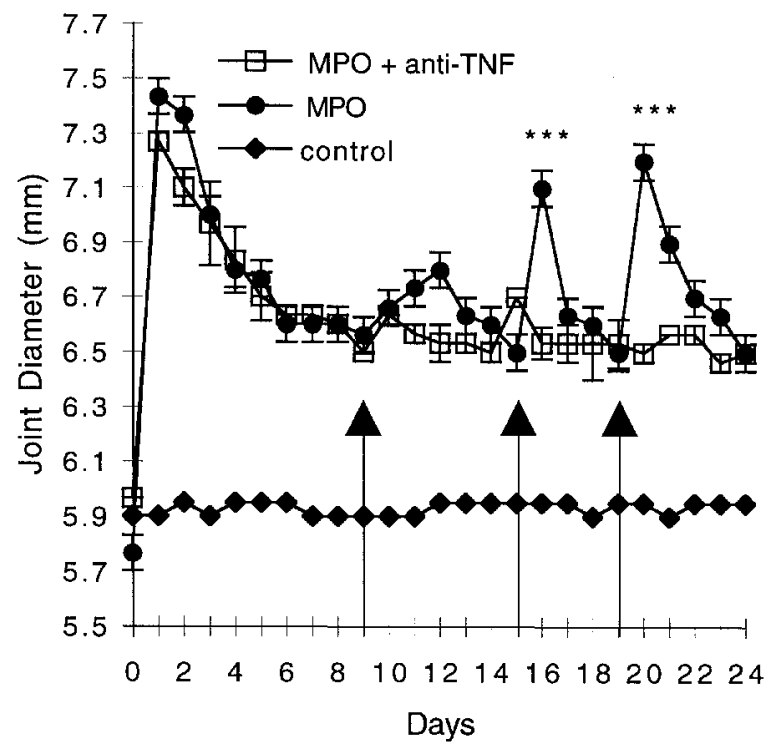

FIG. 3. The inhibition of peri-articular swelling after simultaneously injecting enzymatically active myeloperoxidase (MPO) and anti-tumor necrosis factor-alpha (anti-TNF $\alpha$ ). On day 0 , animals were injected with $10 \mu$ l PG-APS $(2 \mu \mathrm{g}$ of rhamnose/joint) in the left ankle joint and $10 \mu \mathrm{l}$ normal saline in the right ankle joint. After the treated ankle joint returned to 'baseline' levels of swelling and erythema, the re-injecting regimen was started. On days 9, 15, and 19 (as depicted by the arrows), animals were re-injected simultaneously in the left ankle joint with one of the following: $10 \mu \mathrm{l}$ MPO alone $(2 \mu \mathrm{g} /$ joint $)$, or a combination of $5 \mu \mathrm{IMPO}(2 \mu \mathrm{g} / \mathrm{joint})$ and $5 \mu \mathrm{I}$ anti-TNF $\alpha$. The right ankle joint was re-injected with $10 \mu \mathrm{l}$ normal saline. These values represent the results of 3-5 animals. The experiment was repeated at least once. The concentrations reflected in the graph are those injected into the joint. ${ }^{* *} P \leq 0.001$.

those for mannans alone (Fig. 4), i.e. no effect. Similar results were obtained with iMPO (data not shown).

Histological examinations of joints which received the various treatment modalities were done. Table 1 describes the observations obtained. Minimal to no

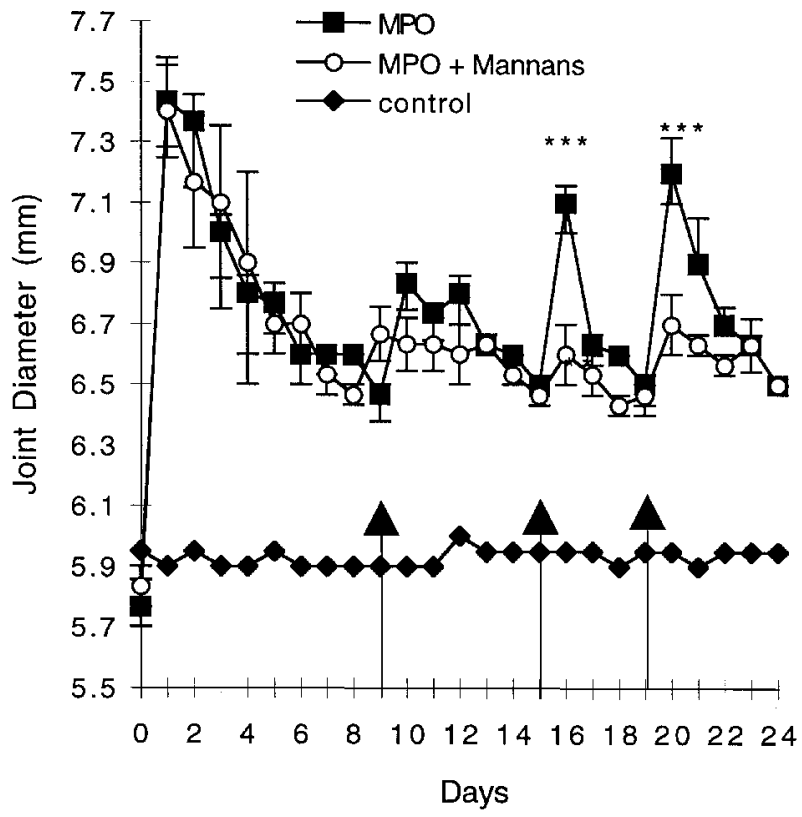

FIG. 4. The inhibition of peri-articular swelling after injecting simultaneously enzymatically active myeloperoxidase (MPO) and mannans. On day 0 , animals were injected with $10 \mu$ l of PG-APS ( $2 \mu \mathrm{g}$ rhamnose/joint) into the left ankle joint and $10 \mu \mathrm{l}$ normal saline into the right ankle joint. After the treated ankle joint returned to 'baseline', the re-injecting regimen was started. On days 9,15 , and 19 (as depicted by the arrows), animals were re-injected simultaneously in the left ankle joint with one of the following: $10 \mu$ I MPO alone $(2 \mu \mathrm{g} / \mathrm{joint})$, or a combination of $5 \mu \mathrm{l} \mathrm{MPO}(2 \mu \mathrm{g} / \mathrm{joint})$ and $5 \mu \mathrm{l}$ mannans. The right ankle joint was re-injected with $10 \mu \mathrm{l}$ of normal saline. Graphed values represent the results of 3-5 animals. The experiment was repeated at least once. The concentrations reflected in the graph are those injected into the joint. ${ }^{* *} P \leq 0.001$.

pathology was noted in joints injected with saline. Minimal pathology did persist at 1 month after a single injection of PG-APS. If MPO was employed as an initiator and injected once a week for 3 weeks at the high dose of $20 \mu \mathrm{g}$ in $10 \mu \mathrm{l}$, the pathology

Table 1

\begin{tabular}{|c|c|c|c|c|c|}
\hline Treatment & $\begin{array}{c}\text { Synovial } \\
\text { hyperplasia }\end{array}$ & $\begin{array}{c}\text { Synovial } \\
\text { inflammation }\end{array}$ & $\begin{array}{c}\text { Percentage } \\
\text { PMN }\end{array}$ & Exudate & Bone erosion \\
\hline 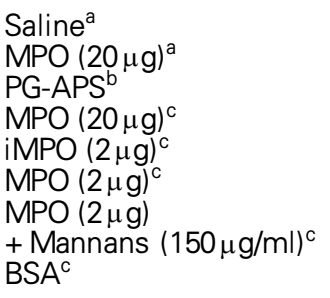 & $\begin{array}{l}0 \\
+ \\
+ \\
++ \\
++ \\
+++ \\
++ \\
+\end{array}$ & $\begin{array}{l}0 \\
+ \\
+ \\
++ \\
+++ \\
+++ \\
++ \\
+\end{array}$ & $\begin{array}{l}0 \\
0 \\
+ \\
+++ \\
++ \\
+ \\
+ \\
+\end{array}$ & $\begin{array}{l}0 \\
0 \\
0 \\
+++ \\
+++ \\
+ \\
+ \\
+ \\
+\end{array}$ & $\begin{array}{l}0 \\
0 \\
0 \\
+++ \\
++ \\
+++ \\
++ \\
+\end{array}$ \\
\hline
\end{tabular}

a Values represent the pathology observed after 3 weekly IA injections without an initial injection of PG-APS.

${ }^{b}$ Pathology at 3 weeks after a single injection of PG-APS and 3 weekly injections of saline.

${ }^{c}$ Values represent the pathology observed after a single $10 \mu \mathrm{l}$ injection of PG-APS followed by 3 IA injections of the stated treatment. Each injection was administered after the joint had returned to baseline level of swelling. Amounts in parenthesis represent the concentration injected in the joint. Data represent the mean of at least 4 different animals.

Key: Synovial hyperplasia; $0=0-2$ layers, $+=3,4$ layers, $++=5,6$ layers, $+++=>6$ layers. Synovial inflammation; $0=<2$ lymph, $+=$ inflamm (not crowded),$++=$ inflamm (cell crowded),$+++=$ diffuse. $\%$ PMN; $0=<1 \%,+=<10 \%,++=11-20 \%,++=>30 \%$. Exudate; $0=<1 \%,+=<10 \%,++=11-20 \%$, $+++=>30 \%$. Bone erosion; $0=$ none,$+=$ only edge $1-2$ joint surfaces or juxta bone,$++=$ more extensive over surface or $2-5$ foci, $+++=$ more extensive or $>5$ foci. 

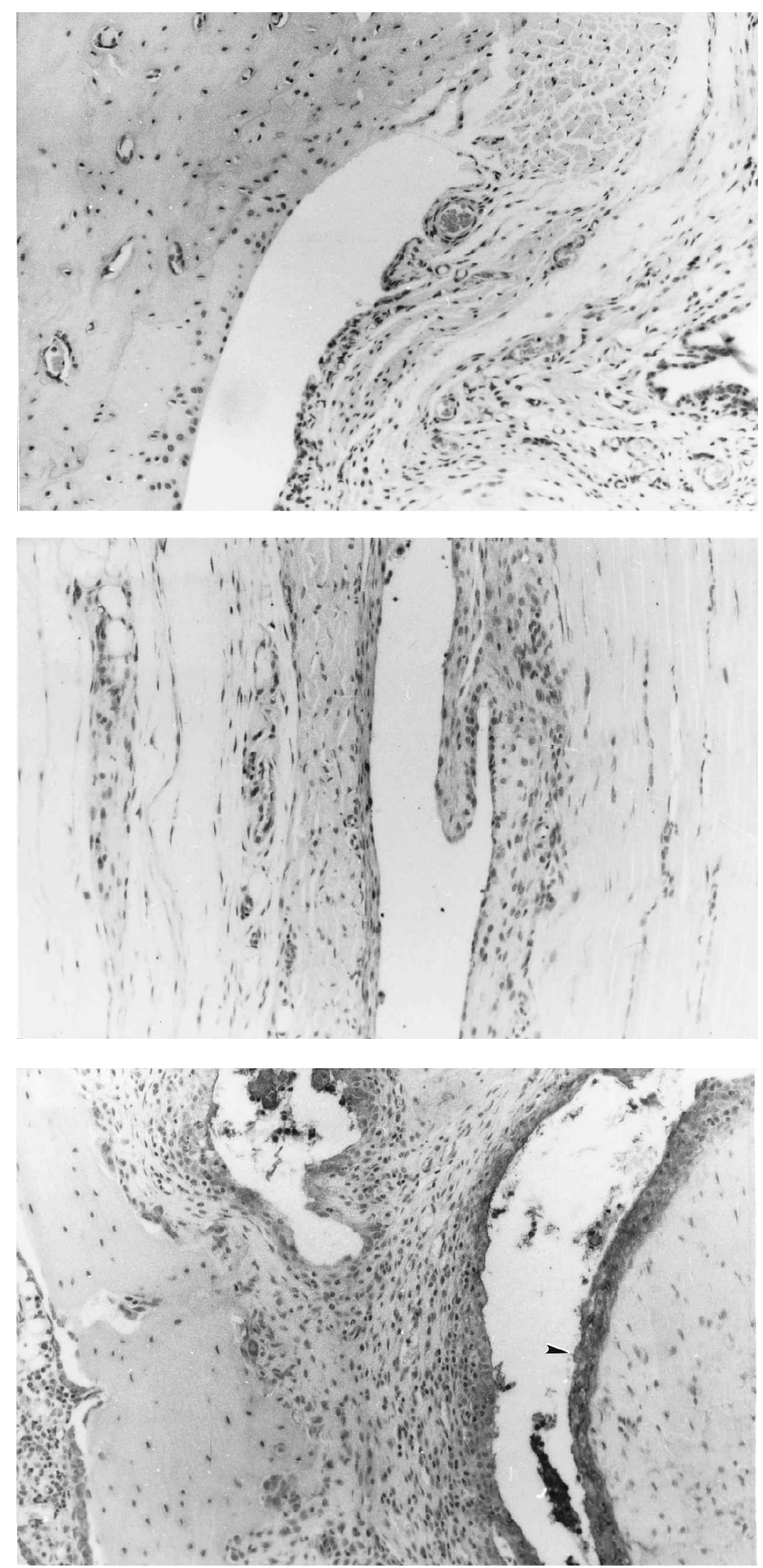

FIG. 5. Photomicrographs showing the detection of tumor necrosis factor-alpha (TNF $\alpha$ ) by immunocytochemical (ICC) methods in the synovial tissue of experimental arthritic joints. Tissue was stained with VECTASTAIN ABC system and counterstained with hematoxylin. (a) Photomicrograph of a 'control' ankle joint which was repeatedly injected with saline. For the purpose of ruling out non-specific binding, sequential cuts of 'control' ankle joints were subjected to either anti-TNF $\alpha$ or normal rabbit lgG. (b) Photomicrograph of a joint injected with a single injection of PG-APS and harvested at the same time as the joints pictured in (a) and (c). (c) Distribution of TNF $\alpha$ positive cells in synovial tissue from rat ankle joints that were primed with PG-APS and reinjected with enzymatically active myeloperoxidase (MPO). 
observed was similar to that observed with a single injection of PG-APS alone (after 3 weeks). That is: the pathology observed after three weeks was agreeable with what has been observed previously in the model. However, if RA was initiated with PG-APS and the joint was subsequently injected with $20 \mu \mathrm{g}$ of MPO, there was extensive pathology (Table 1). If joints were injected once with PG-APS and then with $2 \mu \mathrm{g}$ in $10 \mu \mathrm{l}$ of either MPO or iMPO, the pathology was less severe than that observed with the higher dose of the enzyme. No marked difference in pathology was noted between animals injected with $2 \mu \mathrm{g}$ of either MPO or iMPO. The presence of mannans diminished the overall pathology observed (Table 1).

Since either MPO or iMPO induced clinical and pathological changes consistent with an exacerbation of arthritis, immunocytochemistry studies were done to determine if the Mø-like cells, which comprise the synovial lining of the inflamed joint, were a source of TNF $\alpha$. After initiation of RA with PG-APS and IA injection of either MPO or iMPO, animals were sacrificed and the joints prepared for staining. Figure 5 a show $s$ a section of a joint repeatedly injected with saline. Minimal positive staining was observed in widely spaced areas of the joint. Figure $5 \mathrm{~b}$ shows a section of a joint injected with a single injection of PG-APS. Figure 5c shows a section of a joint injected with PG-APS, allowed to return to baseline, and then repeatedly injected with MPO. Note that those cells lining the joint stained positive for TNFo. If animals were injected with PG-APS followed by repeated injections of $\mathrm{iMPO}$, the staining pattern was essentially the same for TNF $\alpha$ as that obtained when MPO was injected (data not shown). When normal rabbit IgG was employed instead of rabbit anti-TNFa, no non-specific staining was observed.

\section{Discussion}

Numerous cell types including neutrophils, monocytes/Mø, and $\mathrm{T}$ cells have been reported to be present in the synovial fluid of human RA joints. ${ }^{4,6,10,26}$ Also, numerous cytokines are found in the synovial fluid of inflamed joints..$^{2,7,11}$ Of all the cytokines present in an RA joint, it is believed that TNF $\alpha$ is pivotal to the disease since it initiates a cascade of cytokines associated with inflammation. ${ }^{7,10,11}$ Tumor necrosis factor $\alpha$, induces the secretion of IL-1 $^{7,10,11}$ as well as activates osteoclasts in RA joints. ${ }^{7,11}$ Moreover, IL-1 causes loss of prote oglycan from articular cartilage which is one of the hallmarks of human RA. ${ }^{4}$ The presence of TNF $\alpha$ and IL-1 induces secretion of IL-8 and GM-CSF, as well as an infiltration of both neutrophils and monocytes into an arthritic joint. ${ }^{4,27}$ The cytokines, IL-1, TNF $\alpha$ and GM-CSF cause neutrophil degranulation ${ }^{4,28}$ which would provide a continuous supply of both MPO and iMPO to the joint.
Cells of Mø lineage have been reported to be the major source of TNFo in a human RA joint $t^{6,11,29}$ and the intensity of additional Mø migration into the joint correlates with clinical activity of human RA. ${ }^{6}$ When resident rat peritoneal Mø were exposed to either iMPO (Fig. 1) or MPO an increase in TNFo secretion was observed. Tumor necrosis factor induction by iMPO was dose dependent; however, this was not true when MPO was employed. This could be explained in part by the following: MPO induced greater amounts of reactive oxygen intermediates (ROI) than MPO (unpublished data), and that ROI can enhance secretion of a cytokine as well as oxidize receptors ${ }^{30}$ preventing cell signaling causing a reduction of secreted cytokine. Only at the highest concentration of MPO, were the Mø stimulated sufficiently to secrete TNF. Thus, minimal oxidation by iMPO would result in greater cell signaling and consequently higher titers of TNF (approximately 2-fold). These in vitro studies suggest that both $\mathrm{MPO}$ and $\mathrm{M} \mathrm{MPO}$ can interact with $\mathrm{Mø}$ in the microenvironment of an arthritic joint.

It has been established that PMN's within human RA synovial fluid degranulate and secrete MPO into the mic roenvironment. ${ }^{5}$ Within 10 minutes of stimulation of neutrophils, ap prox imately $30 \%$ of their MPO is secreted. ${ }^{31}$ Of the $30 \%$ of the secreted enzyme, only $5 \%$ retains enzymatic activity. ${ }^{31,32}$ Results of other studies indicate that PMN's released approximately $50 \%$ of their MPO at a site of inflammation. Also, with respect to human RA, Davies et al., reported the presence of MPO in arthritic joints. ${ }^{5}$ Moreover, Edwards et al., have reported that there are $16-29 \mu \mathrm{g} / \mathrm{ml}$ of enzymatically inactive MPO in the synovial fluid of a human arthritic joint. ${ }^{15}$ In the present study, the injection of $2 \mu \mathrm{g} /$ joint $(200 \mu \mathrm{g} / \mathrm{ml})$ of the enzyme was the standard concentration employed. Since there is not a consensus among the numerous studies completed to date with respect to the amount of both MPO and iMPO in a human RA joint, concentrations utilized in this study may well be within 'pathological range'.

From $0.2-20 \mu \mathrm{g}$ of MPO injected into a joint did not initiate RA within $24-48 \mathrm{~h}$ after injection, as determined by both clinical and pathological criteria. In this study, IA injections of either MPO or iMPO after PG-APS induced arthritis. The fact that PG-APS, but not MPO or iMPO, could initiate arthritis could be explained in part by the fact that PG-APS is a more potent inducer of TNFo. Also, it is possible that MPO, which is highly conserved in various species, is not highly immunogenic. With respect to prolonged presence of this enzyme and the induction of RA, it has been reported that highly cationic molecules have been associated with retention in joints and arthritogenicity. ${ }^{23}$ Retention is believed to be due to the interaction of the cationic molecule with the negatively charged cartilage. ${ }^{23,34,35}$ 
Since this study involved repeated injections of various treatments into a particular joint, there was concern that the trauma alone of repeated injections could induce inflammation associated with RA. Therefore, BSA and/or saline was repeatedly injected into PG-APS treated joints. The results indicated that repeated injections were not sufficient to induce marked clinical or pathological changes (Table 1).

Exacerbation of an arthritic flare can be induced by a number of exogenous substances such as LPS (at higher doses than those employed in the present study) and microbial superantigens. ${ }^{33}$ The purpose of 'cycling' the injections of either MPO or iMPO after an initial injection of PG-APS $w$ as to simulate flares of the disease which occurs in patients (Figs $2 \mathrm{a}$ and b). As stated previously, the first injection of MPO, after PGAPS, did not induce a positive flare whereas the first injection of iMPO did induce an exacerbation of the disease. A possible explanation for this could be the fact that MPO induces tissue damage through ROI. ${ }^{30}$ Therefore, the first injection would result in predominantly tissue damage and subsequent immune cell recruitment. However, with the second injection, immune cells would now be present in the joint and would induce higher titers of TNFa. With iMPO, an initial injection would favor induction of proinflammatory cytokines and rapid recruitment of immune cells and not direct tissue damage due to ROI.

Shepherd and Hoidal reported that MPO binds to Mø via a specific receptor, the $M M R{ }^{24}$ Therefore, if either MPO or iMPO was causing an exacerbation of experimental arthritis and contributing to 'chronicity' of the disease, then inhibiting the binding of this enzyme should ameliorate clinical symptoms. When either MPO or iMPO were injected simultaneously with mannans, there was no exacerbation of clinical disease (Fig. 4) providing evidence for the importance of Mø-MMR-neutrophil (i.e. MPO or iMPO) interaction. Pathology reports corroborated these results (Table 1). Since PG-APS is a polymer of acetylated mannose, the same concept was applied to the model itself. If MMR-PG-APS interaction was sufficient to induce $\mathrm{RA}$, then via competitive binding, mannans should diminish or prevent the initiation of the disease. When PG-APS was injected simultaneously with mannans, there was no clinical response observed. Again this indicates a central role of the MøMMR ligand interaction in the induction of arthritis using this animal.

Synovial type A cells, which are of Mø lineage, are a major source of TNFo in arthritic joints. ${ }^{8}$ Using immunocytochemistry, TNF $\alpha$ was found only among the mononuclear phagocytic cells of the lining of the joint, in perivascular areas, and in the pannus ${ }^{22}$ of joints injected with PG-APS followed by injection of either MPO or iMPO. These results indicate that either MPO or iMPO interacting with cells of the synovial lining, which are of Mø-lineage, induce the production of TNFa. Also, the pattern of TNFo staining parallels that observed in human RA.

Various investigators have reported that $\mathrm{T}$ cells participate in the pathological events of RA. ${ }^{36,37}$ However, recognition of the neutrophil as a major contributor to the pathology associated with RA has only recently been reported. ${ }^{26}$ The results of the present study have described the importance of the neutrophil-Mø interaction in exacerbation of inflammation associated with a model of arthritis. These results indicate that: (1) either MPO or iMPO induce the secretion of TNF $\alpha$ by rat Mø in vitro or in vivo; (2) neither form of the enzyme can initiate RA in the rat model; (3) numerous exacerbations of arthritis are initiated by repeatedly injecting either MPO or iMPO into a joint pre-treated with PG-APS; (4) immunocytochemistry studies indicated the presence of TNFo; (5) the presence of anti-TNF $\alpha$ inhibits either MPO or iMPO induced ex acerbation of PG-APS-induced arthritis, and (6) clinical and pathological symptoms of arthritis can be ameliorated or ablated by blocking the MMR which is one of the major receptors involved in the uptake of this peroxidase by the Mø.

In conclusion, there appears to be a previously unrecognized interaction of either MPO or iMPO with Mø which could partially explain the 'chronicity' of inflammation observed in this model. A recent report indicated that 'the products of the $M P O-\mathrm{H}_{2} \mathrm{O}_{2}-\mathrm{Cl}$ pathway can act as immunological modifiers providing a further pathway linking acute and chronic inflammation and innate and adaptive immune responses'? Further studies are needed in order to answer the question as to whether this interaction plays a role in 'chronic' inflammation associated with human RA.

\section{References}

1. McInnes IB, Liew FY. Interleukin 15: A proinflammatory role in rheumatoid arthritis synovitis. Im munol Today 1998; 19(2): 75-79.

2. Winchester R. Rheumatoid arthritis. In: Frank MM, Claman HN, Ansten KF, Unanue ER, eds. Samter's Im munologic Diseases. 5th edn. New York: Little Brown Publishers, 1995; 699-757.

3. Mc Innes IB, Sturrock D. Mechanisms and models in rheumatoid arthritis. In: Henderson B, Edwards JCW, Pettipher ER, eds Clinical Aspects of Rheumato id Arthritis. San Diego: Academic Press, 1995; 3-24.

4. Otterness IG, Van de Loo FAJ, Bliven L. Mechanisms and models in rheumatoid arthritis. In: Henderson B, Edwards JCW, Pettipher ER, eds Cytokines in Models of Arthritis. San Diego: Academic Press, 1995; 485-505.

5. Davies EV, Williams BD, Campbell AK. Synovial fluid polymorphonuclear leukocytes from patients with rheumatoid arthritis have reduced MPO and NADPH-oxidase activity. Br J Rheumatol 1990; 29: 415-421.

6. Burmester GR, Stuhlmuller B, Keyszer G, Kinne RW. Mononuclear phagocytes and rheumatoid synovitis. Mastermind or workhorse in arthritis? Arthritis Rheum 1997; 40(1): 5-18.

7. Brennan FM, Maini RN, Feldmann M. TNF $\alpha-A$ pivotal role in rheumatoid arthritis? Br J Rheumatol 1992; 31: 293-298.

8. Cutolo M, Sulli A, Barone A, Seriolo B, Accardo S. Macrophages, synovial tissue and rheumatoid arthritis. Clin Exp Rheumatol 1993; 11: $331-339$.

9. Marcinkiew icz J. Neutrophil Chloramines: missing links between innate and acquired immunity. Im munol To day 1997; 18(12): 577-580.

10. Feldmann M, Brennan FM, Maini RN. From the laboratory to the clinic: Evaluation of cytokines in rheumatoid arthritis highlights TNF- $\alpha$ as a new therapeutic target. The Im munologist 1994; 215: 172-176. 
11. Feldmann M, Brennan FM, Maini RN. Role of cytokines in rheumatoid arthritis. Ann Rev Immunol 1996; 14: 397-440.

12. Sewell KL, Trentham DE. Pathogenesis of rheumatoid arthritis. Lancet 1993; 341: 283-290.

13. Kunkel SL, Lukacs N, Kasama T, Strieter RM. The role of chemokines in inflammatory joint disease. J Leuk Biol 1996; 59: 6-11.

14. Bradley PP, Christensen RD, Rothstein G. Cellular and extracellular myeloperoxidase in pyogenic inflammation. Blood 1982; 60(3): 618-622.

15. Edwards SW, Hughes V, Barlow J, Bucknall R. Immunological de tection of myeloperoxidase in synovial fluid from patients with rheumatoid arthritis. Biochem J 1988; 250: 81-85.

16. Lincoln JA, Lefkowitz DL, Cain T, Castro A, Mills KC, Lefkowitz SS, Moguilevsky N, Bollen A. Exogenous myeloperoxidase enhances bacterial phagocytosis and intracellular killing by macrophages. Infect Im $m u n$ 1995; 63(8) : 3042-3047.

17. Lefkowitz SS, Gelderman MP, Lefkowitz DL, Moguilevsky N, Bollen A. Phagocytosis and intracellular killing of Candida albicans by macrophages exposed to myeloperoxidase. J Infect Dis 1996; 173: $1202-1207$.

18. Gelderman MP, Lefkowitz DL, Lefkowitz SS, Bollen A, Moguilevsky N. Exposure of macrophages to an enzymatically inactive macrophage mannose receptor ligand augments killing of Candida albicans. Soc Exp Biol Med 1998; 217(1): 81-88.

19. Mills KC, Lefkow itz DL, Morgan CD, Lefkow itz SS. Induction of cytokines by peroxidases in vivo. Im munol Infect Dis 1992; 2: 45-50.

20. Lichtman SN, Wang J, Balfour, Sartor R, Zhang C, Bender D, Dalldorf FG, Schwab JH. Reactivation of arthritis induced by small bowel bacterial overgrowth in rats: Role of cytokines, bacteria, and bacterial polymers. Infect Im mun 1995; 63(6): 2295-2301.

21. Wahl SM, Allen JB, Costa GL, Wong HL, Dasch JR. Reversal of acute and chronic synovial inflammation by anti-transforming grow th factor $\beta$. J Exp Med 1993; 177: 225-230.

22. Chu CQ, Field M, Feldmann M, Maini RN. Localization of tumor necrosis factor $\alpha$ in synovial tissues and at the cartilage-pannus junction in patients with rheumatoid arthritis. Arthritis Rheum 1991; 34(9): 1125-1132.

23. Mertz AKH, Batsford SR, Curschellas E, Kist MJ, Gondoif KB. Cationic Yersinia antigen-induced chronic allergic arthritis in rats. A model for reactive arthritis in humans. J Clin Invest 1991; 87: 632-642.

24. Shepherd VL, Hoidal JR. Clearance of neutrophil-derived myeloperoxidase by the macrophage mannose receptor. Am J Respir Cell Mol Biol 1990; 2: 335-340.
25. Sung SJ, Nelson RS, Silverstein SC. Yeast mannans inhibit binding and phagocytosis of zymosan by mouse peritoneal macrophages. J Cell Biol 1983; 96: 160-166.

26. Edwards SW, Hallett MB. Seeing the wood for the trees: the forgotten role of neutrophils in rheumatoid arthritis. Immunol Today 1997; 18: $320-324$.

27. Rathanasw ami P, Hachicha M, Wong WL, Schall TJ, Mc Coll SR. Synergistic effect of interleukin- $\beta$ and tumor necrosis factor $\alpha$ on interleukin- 8 gene expression in synovial fibroblasts. Arthritis Rheum 1993; 36(9): 1295-1304.

28. Gasson JC. Molecular physiology of granulocyte-macrophage colonystimulating factor. Blood 1991; 77(6): 1131-1145.

29. Gaston JSH. The role of infection in inflammatory arthritis. QJ Med 1994; 87: 647-651.

30. Bozeman PM, Hoidal JR, Shepherd VL. Oxidant-mediated inhibition of ligand uptake by the macrophage mannose receptor. J Biol Chem 1988; 263(3): $1240-1247$.

31. Edwards SW, Nurcombe HL, Hart CA. Oxidative inactivation of myeloperoxidase released from human neutrophils. Biochem $J$ 1987; 245: $925-928$.

32. King CC, Jefferson MM, Thomas EL. Secretion and inactivation of myeloperoxidase by isolated neutrophils. J Leuk Biol 1997; 61: $293-300$.

33. Schwab JH. Bacterial cell-wall induced arthritis: Models of chronic recurrent polyarthritis and reactivation of monoarticular arthritis. In: Henderson B, Edwards JCW, Pettipher ER, eds Mechanisms and Models in Rheumatoid Arthritis. San Diego: Academic Press, 1995; 431-446.

34. Van Lent PLEM, Blom A, Holthuysen AEM, Jacobs CWM, Van de Putte LBA, Van den Berg WB. Monocytes/macrophages rather than PMN are involved in early cartilage degradation in cationic immune complex arthritis in mice. J Leuk Biol 1997; 61: 267-278.

35. Van den Berg WB, Van de Putte LBA, Zwarts WA, Joosten LAB. Electrical charge of the antigen determines intra-articular antigen handling and chronicity of arthritis in mice. J Clin Invest 1984; 74: 1850-1859.

36. Gay S, Gay RE, Koopman WJ. Molecular and cellular mechanisms of joint destruction in rheumatoid arthritis: two cellular mechanisms explain joint destruction? Ann Rheum Dis 1993; 52: S39-S47.

37. Snowden N, Reynolds I, Morgan K, Holt L. T cell responses to human type II collagen in patients with rheumatoid arthritis and healthy controls. Arthritis Rheum 1997; 40(7): 1210-1218.

\section{Received 6 July 1998}




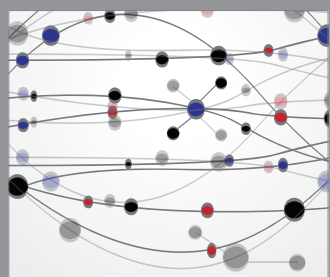

The Scientific World Journal
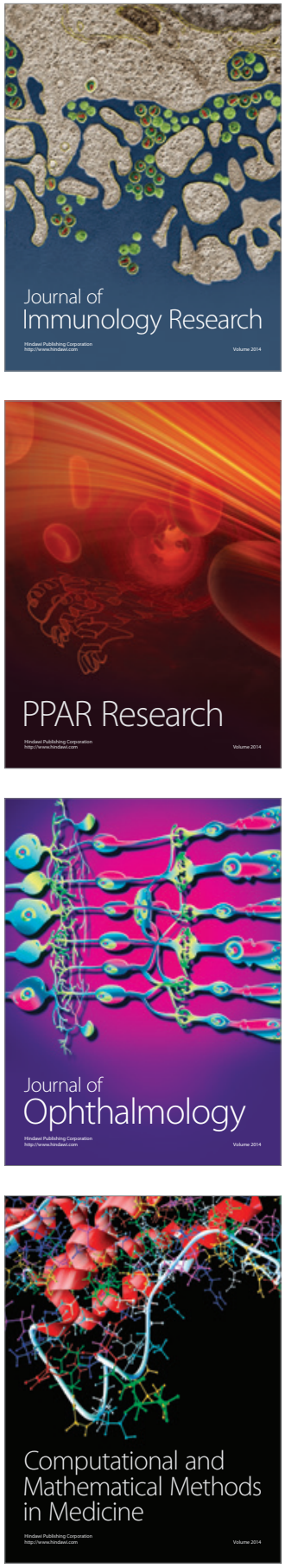

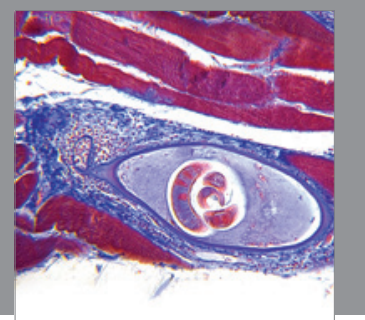

Gastroenterology

Research and Practice
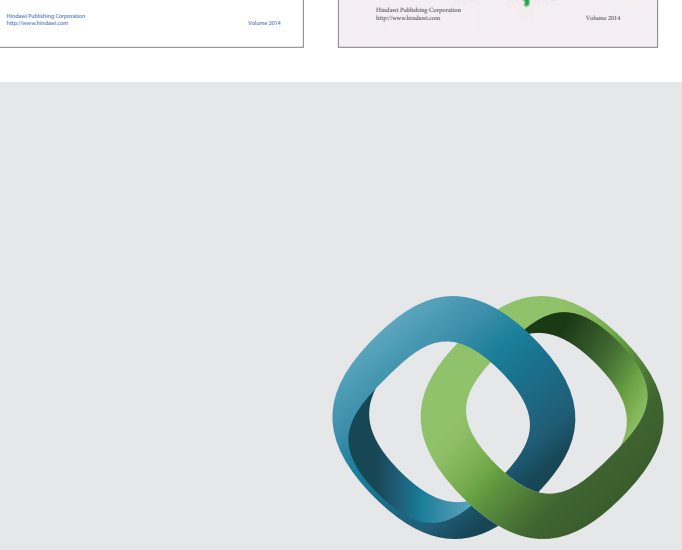

\section{Hindawi}

Submit your manuscripts at

http://www.hindawi.com
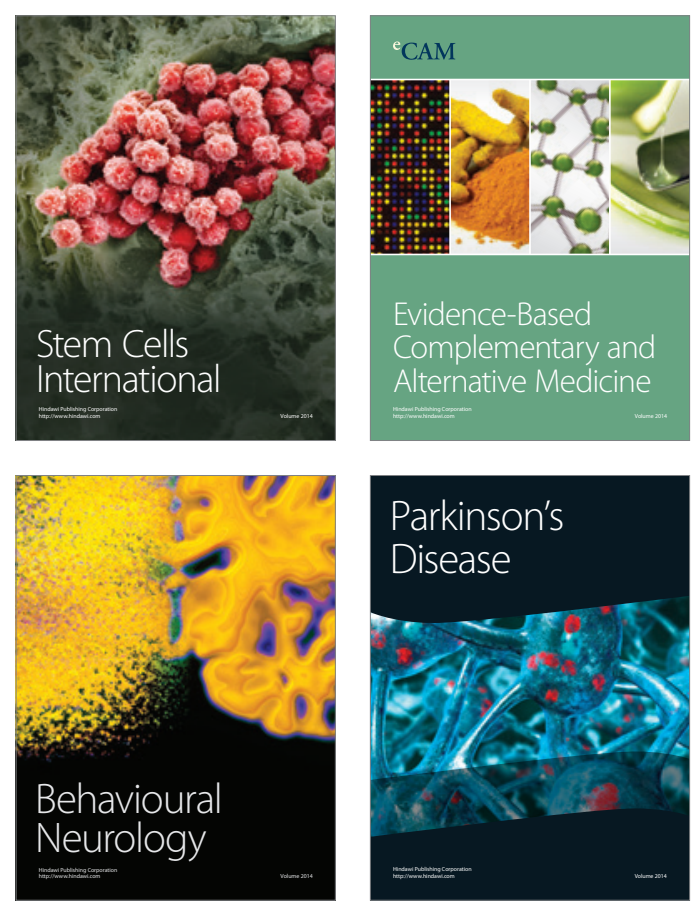

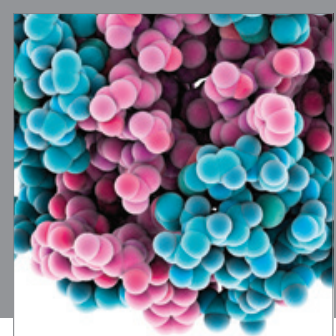

Journal of
Diabetes Research

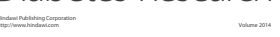

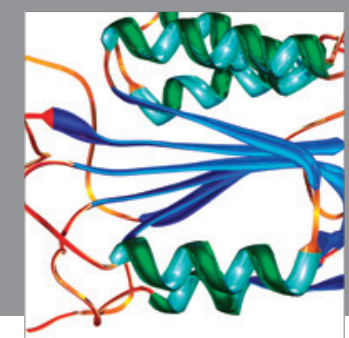

Disease Markers
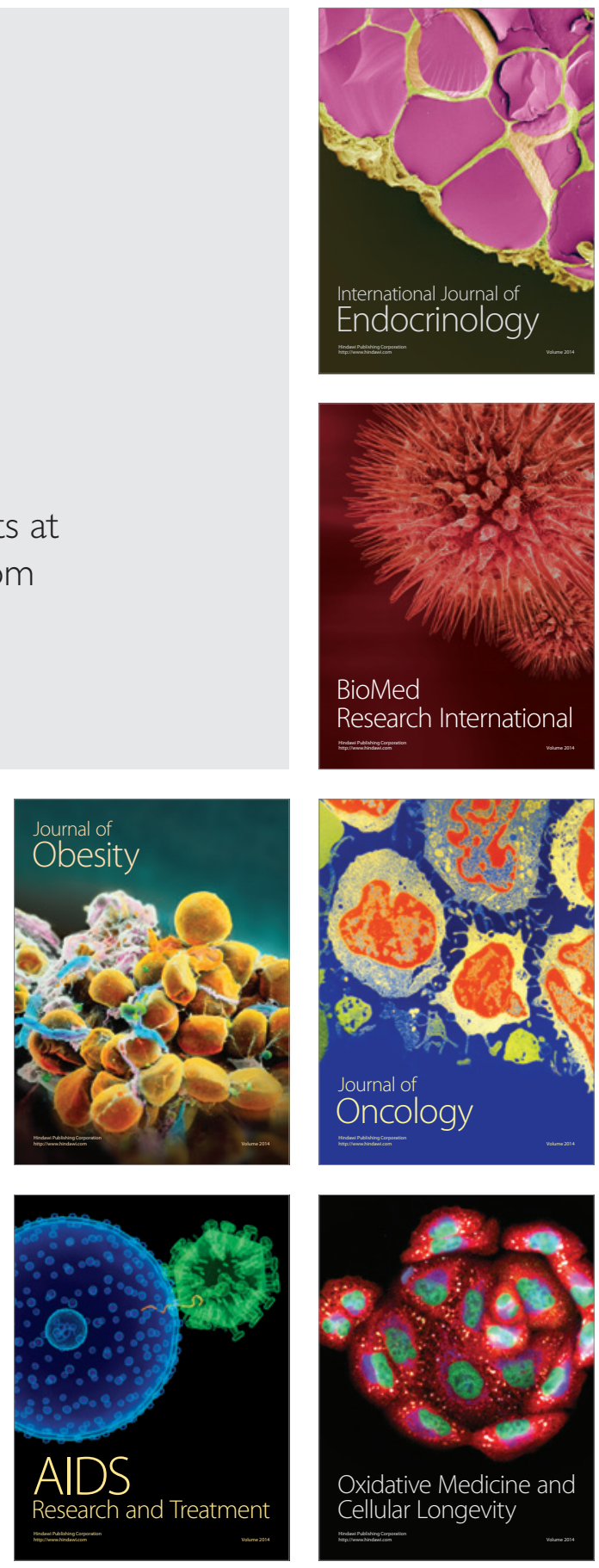